\title{
Descortinando a vivência emocional do parto através do Método Bick
}

\author{
Tagma Marina Schneider Donelli - Universidade Federal do Rio Grande do Sul - UFRGS, Porto Alegre-RS, Brasil \\ Rita de Cássia Sobreira Lopes - Universidade Federal do Rio Grande do Sul - UFRGS, Porto Alegre-RS, Brasil
}

\begin{abstract}
Resumo
O presente estudo aplicou o Método Bick, para fins de pesquisa, com o objetivo de desvendar e conhecer a vivência emocional da mulher sobre o parto. Foram realizadas observações em um centro obstétrico durante dezenove meses. As observações foram relatadas, supervisionadas e posteriormente analisadas. Os dados apontam o parto como um momento potencialmente desorganizador, capaz de produzir sobrecarga emocional e desencadear estado de vulnerabilidade psíquica nas mulheres, produzindo impacto emocional também no observador e na equipe. Foi constatado o uso de mecanismos defensivos na equipe, que prejudicava a interação profissional-paciente. A aplicação do Método Bick possibilitou a aproximação da vivência emocional do parto através da disponibilidade psíquica e da postura não-intrusiva do observador. O estudo sugere a necessidade de revisar práticas relacionadas ao manejo dos aspectos emocionais das parturientes. Implicações clínicas e para a pesquisa também são abordadas.

Palavras-chave: Método Bick, Parto, Centro obstétrico, Assistência ao parto.
\end{abstract}

Unveiling the emotional experience of delivery through the Bick Method

\begin{abstract}
This study is an application of the Bick method to research aiming at revealing and investigating women's emotional experience of delivery. Observations were carried out in an obstetric ward during nineteen months. The observations were reported, supervised and later analyzed. The results revealed that delivery is a potentially disorganizing moment. Due to women's regressive condition, it may produce emotional overload and trigger a state of psychic vulnerability in women, which has an emotional impact on the observer and the professionals. The use of defensive mechanisms by the professionals was observed which interfered in the professional-patient interaction. The observer's psychic availability and non-intrusive position, which characterize the Bick method, enabled him/her to get in contact with the emotional experience of delivery. The study suggests the need for revising professional practices related to the handling of the emotional aspects of delivery. Both clinical and research implications of the findings are discussed.

Keywords: Bick method, Delivery, Obstetric ward, Assistance.
\end{abstract}

\section{Revelando la experiencia emocional del parto por el Método Bick}

\begin{abstract}
Resumen
Este estudio aplicó el método Bick, para propósitos de investigación, con el fin de desvanecer y comprender la experiencia emocional de las mujeres sobre el parto. Las observaciones se realizaron en un centro obstétrico durante diecinueve meses. Las observaciones fueron reportadas, monitoreadas y posteriormente analizadas. Los datos apuntaron el parto como un momento potencialmente disruptivo, capaz de producir una sobrecarga y provocar el estado emocional de vulnerabilidad psíquica de las mujeres, produciendo impacto emocional también en el observador y en el equipo. Se observó el uso de mecanismos defensivos en el equipo, lo que socavaría la interacción profesional-paciente. La aplicación del método Bick posibilitó la aproximación de la experiencia emocional del parto a través de la disponibilidad y de la postura psicológica y no intrusiva del observador. El estudio sugiere la necesidad de revisar las prácticas relacionadas con la gestión de los aspectos emocionales de las parturientes. Se discuten las implicaciones clínicas y para la investigación. Palabras clave: Método Bick, Parto, Centro obstétrico, Atención al parto.
\end{abstract}

Tornar-se mãe e pai é uma importante etapa evolutiva da vida adulta (Colarusso, 1990), assim como tornar-se avós, mais tarde (Colarusso, 1997). O pai e a mãe revivem as etapas iniciais do desenvolvimento, agora na posição de genitores, o que provoca sentimentos intensos (Caron, Fonseca \& Lopes, 2008) e representa oportunidade de amadurecimento ou de separação-individuação em relação aos próprios pais (Colarusso, 1990; Levandowski, Piccinini \& Lopes, 2009). É também uma oportunidade de elaborar conflitos internos e de relacionamento (Birksted-Breen, 2000). No presente artigo, será focalizado o momento do parto e seu potencial para reativar emoções e formas de comunicação primitivas na mulher. A importância da assistência à mulher nesse momento será também explorada.

Disponivel em monv.scielo.br
Desde o final da gestação, a mãe passa a apresentar uma condição especial, chamada por Winnicott (1956/2000) de preocupação materna primária. Nesse estado, a mulher se apresenta regredida e fragilizada e sua sensibilidade fica aumentada, o que permite sua identificação com o bebê. Essa forma de empatia materna é extremamente sofisticada e importante no período inicial de desenvolvimento, permitindo que a mãe, que já foi bebê, se reconecte com as vivências emocionais primitivas do seu filho recém-nascido. Assim, o nascimento de um filho remete a mulher ao seu próprio nascimento (Donelli, Caron \& Lopes, 2012).

Em razão da condição regressiva da mãe, de maior fragilidade, é importante refletir também sobre a importância da assistência à mulher nesse contexto. $\mathrm{Na}$ 
literatura psicanalítica são encontrados inúmeros autores que se dedicaram à questão da importância de uma figura materna capaz de proteger o bebê do excesso de estímulos e da sobrecarga emocional decorrente como uma condição para o adequado e saudável desenvolvimento emocional no início da vida (Anzieu, 2000; Bick, 1968/2002; Bion, 1962/1991; Klein, 1969; Winnicott, 1956/2000, 1960/1990, 1963/1990, 1972/1991). De forma análoga, mas infinitamente menos explorada, se coloca a questão do cuidado e da proteção necessários às mulheres que estão vivenciando o ciclo gravídico-puerperal e, mais especificamente, que estão dando à luz. O movimento de transferência do parto para os hospitais, a medicalização do evento e as práticas médicas que visam à excelência tecnológica acabam desumanizando as relações entre profissionais e pacientes, abrindo espaço para as reflexões sobre esse tema.

Os estudos sobre o parto, com algumas exceções (Donelli, 2003; Lopes, Donelli, Lima \& Piccinini, 2005; Marin, Donelli, Lopes \& Piccinini, 2009), não o têm abordado a partir da perspectiva proposta no presente estudo, isto é, uma perspectiva evolutiva, que o considera como parte integrante do processo de tornarse mãe. Em geral baseados em metodologia quantitativa, os estudos o investigam como um evento passível de ser estudado mediante o controle de suas variáveis e têm reforçado a polarização da experiência em boa ou má. A tendência é de tratar o parto como um evento isolado, passível de controle pela tecnologia médica e contra o qual mulheres e profissionais da saúde devem se proteger. Tal necessidade de proteção parece se voltar, especialmente, contra a dor, a morte, a perda e sentimentos regressivos suscitados pela vivência do parto, a qual remete todo ser humano ao próprio nascimento (Czarnocka \& Slade, 2000; Durik, Hyde \& Clark, 2000; Melender, 2002; Ryding, Wijma \& Wijma, 2000; Soet, Brack \& Dilorio, 2003; Terry \& Gijsbers, 2000).

Portanto, faz-se necessária a realização de um estudo que se proponha a desvendar e conhecer a vivência emocional do parto, tendo como foco a mulher que dá à luz. Para tanto, propõe-se investigar a experiência do parto através de uma aplicação do método de observação proposto por Bick (1964). Esse método foi originalmente desenvolvido para auxiliar na formação de psicoterapeutas e psicanalistas de crianças, bem como para servir como auxiliar ao estudo da psicanálise, especialmente de crianças, constituindo-se, ao longo dos anos, em uma ferramenta importante para a formação de analistas infantis. A observação semanal de um bebê e de sua mãe, realizada no seio da família e posteriormente relatada e supervisionada em grupo, permitiria compreender mais claramente a experiência infantil de seus pequenos pacientes, além de entender melhor a conduta não-verbal e os jogos das crianças, bem como ajudar a decifrar as informações das mães sobre a história de cada filho (Bick, 1964).

O método em questão privilegia a compreensão da situação, mais do que o agir ou intervir. Desenvolvido com base em princípios técnicos psicanalíticos, apoia-se em conceitos como atenção flutuante, transferência e contratransferência. Despojando-se de preconceitos teóricos e préjulgamentos morais, o observador coloca-se como observador participante, tendo o cuidado de produzir o mínimo de interferência possível, para assim, captar o inesperado.

Seu uso em pesquisa tem sido cada vez mais difundido (Lopes, Vivian, Oliveira-Menegotto, Donelli \& Caron, 2007; Oliveira-Menegotto, Menezes, Caron \& Lopes, 2006; Rustin, 1997, 1989). O método vem sendo aplicado para observar contextos diversificados, como ultrassonografias obstétricas (Piontelli, 1995; Caron \& cols., 2008), creche (Jardin, Detry, Denis, Moreau \& Silbermann, 1997), família numerosa (Vivian, 2006), bebê com Síndrome de Down (Oliveira-Menegotto, 2007), bebê prematuro em UTI Neonatal (Steibel, 2011) e enfermaria de cardiologia pediátrica (Martini, 2000).

Em relação aos trabalhos que utilizaram observação, foi feito um levantamento nas bases de dados EBSCO, Scopus e PsycNET (Psycinfo), procurando artigos que incluíssem os termos infant observation AND childbirth. Foram localizados, respectivamente, zero, cinco e 17 trabalhos, mas nenhum utilizou o Método Bick para observar o parto. Em nível nacional, foram consultadas as bases SciELO, IndexPSI e Google Acadêmico, utilizando os termos Método Bick AND parto, tendo sido encontrados trabalhos que faziam referência apenas ao Método Bick como método de observação, sem incluir o parto.

Dessa forma, percebe-se a carência de estudos observacionais sobre o parto, pois todos os trabalhos referidos anteriormente utilizaram questionários, entrevistas ou outros instrumentos padronizados aplicados antes ou após o evento do nascimento do bebê, ou se basearam em relatos retrospectivos sobre o parto. Entretanto, para investigar um evento da vida da mulher que remete a vivências primitivas e no qual a linguagem predominante é a não-verbal, o Método Bick parece ser especialmente indicado, por possibilitar o acesso ao mundo intrapsíquico. Pelas características do fenômeno estudado neste trabalho, a utilização do Método Bick foi capaz de fazer emergir dados que talvez outro instrumento não conseguisse. É o caso de uma entrevista, por exemplo. $\mathrm{O}$ fato de ter que traduzir em palavras uma experiência que, num primeiro 
momento, pode não comportar esse tipo de tradução, poderia impedir o acesso a conteúdos importantes relativos ao evento.

Pelo exposto, especialmente pelo fato de não terem sido encontrados estudos observacionais sobre o parto, justifica-se a necessidade de realização de um estudo que se proponha a desvendar e conhecer a vivência emocional da mulher durante o parto. A escolha de aplicar o método Bick de observação de bebês (Bick, 1964) para viabilizar tal investigação justifica-se principalmente por ser o parto um evento da vida da mulher que remete a vivências primitivas, nas quais a linguagem predominante é a não-verbal. Assim, o objetivo geral deste trabalho é desvendar e conhecer, mediante a observação, a vivência emocional da mulher que dá à luz, bem como refletir sobre a assistência dada à mulher nesse contexto.

\section{Método}

Delineamento

Foi utilizado delineamento de estudo de caso único, no qual o caso estudado foi o Centro Obstétrico (CO) de um hospital público da região sul do Brasil. Esse delineamento, tendo como alvo o Centro Obstétrico, permitiu uma aproximação à vivência emocional da mulher sobre o parto, além de compreender questões relacionadas ao setor e às relações que se estabeleceram entre profissionais e pacientes que transitaram pelo local durante a realização do trabalho.

\section{Participantes}

Foram consideradas participantes deste estudo as pacientes internadas em $\mathrm{CO}$ durante a realização das observações, totalizando 112 mulheres. Destas, 41 estavam em trabalho de parto e 15 delas deram à luz durante as observações. Outras oito mulheres estavam internadas por trabalho de parto prematuro, 13 mulheres estiveram internadas em virtude de abortamento e uma por gravidez ectópica (fora do útero), o que exigiu procedimento em Bloco Cirúrgico (BC). Quatro mulheres por ameaça de aborto, cinco estavam em observação por problemas clínicos, como gastrite, asma e infecção urinária; outra por problemas ginecológicos e sete mulheres ficaram internadas no Centro Obstétrico, em observação, por pressão alta. Seis mulheres estavam no setor aguardando o chamado do Bloco Cirúrgico para fazer uma cesariana. Quatro mulheres foram examinadas, mas não permaneceram no setor e seis já haviam passado pelo parto e aguardavam, dentro do Centro Obstétrico, o chamado da unidade de internação para serem transferidas. Ainda, duas mulheres que participaram das observações estavam aguardando resultados de exames:

Psico-USF, Bragança Paulista, v. 18, n. 2, p. 289-298, maio/agosto 2013 uma delas faria uma ultrassonografia e outra havia feito um MAP1.

Também foram considerados participantes a equipe de profissionais, formada por diferentes médicos, enfermeiros e técnicos em enfermagem, estagiários de diversas áreas e pessoal de apoio (sete médicos obstetras, um médico intensivista, cinco pediatras, quatro enfermeiros e nove técnicos em enfermagem, dois funcionários responsáveis pela higienização e também professores e estagiários dos cursos de técnico em enfermagem, de graduação em enfermagem e em fisioterapia). A equipe fixa do turno em que ocorriam as observações era composta por dois médicos, quatro técnicos em enfermagem, um enfermeiro e um funcionário da higienização. Tal inclusão de participantes se justifica tendo em vista que o delineamento deste estudo, de caso único, contemplou a investigação do fenômeno do parto em um Centro Obstétrico onde as parturientes estavam em constante relação com esses profissionais. Tal particularidade é especialmente importante na utilização do Método Bick, que busca apreender a atmosfera emocional oriunda das relações que se estabelecem em um determinado contexto.

A observadora e o grupo de supervisão, formado por uma psicanalista, supervisora do Método Bick, pela orientadora acadêmica deste trabalho e por mais duas colegas que aplicaram o Método Bick em diferentes contextos, também foram considerados participantes, pelas especificidades do método utilizado. A observadora já tinha treino prévio no método Bick padrão.

\section{Procedimentos}

Durante dezenove meses, foram realizadas observações semanais no Centro Obstétrico, sempre no mesmo dia e horário, com duração aproximada de duas horas. Depois de cada observação, foi feito um relato, o mais próximo possível da experiência original, buscando explorar o tom emocional presente na ocasião. Tais relatos foram posteriormente supervisionados em grupo, uma vez por semana, com a coordenação de uma analista experiente. Ao todo, foram escritos oitenta e um relatos de observação. Após cada reunião, foi produzido um relato da sessão de supervisão, feito por uma colega do grupo, designada relatora. Esse relato de supervisão foi sempre lido e revisto antes da leitura do relato de observação seguinte.

Cabe destacar que o projeto do presente estudo foi submetido ao Comitê de Ética em Pesquisa da

\footnotetext{
1 Cardiotocografia ou Monitorização Anteparto Fetal: exame não-invasivo utilizado para avaliação do bem-estar fetal (Mascaro e cols., 2002).
} 
Universidade Federal do Rio Grande do Sul (UFRGS), vinculado à Pró-Reitoria de Pesquisa (PROPESQ), sob $\mathrm{n}^{\circ}$ 479, o qual obteve aprovação. Assim, pode-se pressupor que o presente estudo está em conformidade com as exigências éticas e metodológicas esperadas de uma pesquisa com seres humanos.

\section{Resultados e Discussão}

Ao longo das observações, a observadora experimentou uma aproximação gradual em relação às mulheres participantes do estudo e à vivência emocional do parto, e os três eixos a seguir explicitados, oriundos da análise dos conteúdos gerados pelos relatos das observações e das supervisões, são como camadas que foram sendo retiradas, uma a uma, mediante o olhar insistente lançado sobre o fenômeno do parto. Num primeiro momento, a observadora vivenciou forte impacto emocional diante do ambiente no qual ocorreram as observações (Eixo I). Aos poucos, foi tomando contato com a rotina num Centro Obstétrico (Eixo II), até conseguir se aproximar da vivência emocional das mulheres (Eixo III). Destaca-se que esse descortinamento foi possibilitado pelo próprio Método Bick, que se apoia nos sentimentos contratransferenciais do observador.

O Eixo I, denominado "O Método Bick aplicado à instituição hospitalar: a instituição como um envelope que contém e protege ou como um obstáculo ao contato?", abordou, primeiramente, o desafio de deparar-se com o ambiente hospitalar, com todas as suas características e particularidades, como ilustra a seguinte vinheta:

Consegui cruহar a sala, mas por insistência da minha intermediária, que queria me mostrar onde ficavam as salas de parto. Fui, meio constrangida, achando que devia estar com outra roupa, on quem sabe en deveria era ficar parada, para não sentir que poderia estar atrapalhando alguma coisa. (Obs.01)

De uma forma geral, foram percebidos inúmeros comportamentos defensivos, tanto por parte da equipe quanto por parte da própria observadora, e entendidos como necessários para proteger-se da invasão de sentimentos desagradáveis e ansiogênicos despertados pelo contato próximo e constante com a experiência do parto: "Enquanto fazia o procedimento, [a técnica em enfermagem] conversava comigo e com [a parturiente], e parecia estar ligada no piloto automático.” (Obs.62)

Neste eixo de análise, impôs-se a questão de como cuidar das mulheres prestes a dar à luz, de tal forma que elas se sentissem encorajadas, confiantes, seguras e também assistidas o suficiente para prestar os cuidados necessários ao próprio filho. Pode-se pensar na necessidade da mãe de ser cuidada para poder cuidar (Winnicott, 1957/1999).

A resposta a essa questão talvez passe pela revisão das práticas profissionais, pela formação do profissional da saúde e pelo respaldo emocional que é oferecido a esse profissional em razão da característica das tarefas que desempenha. Médicos, enfermeiros e técnicos em enfermagem que lidam diariamente com mulheres em situação de gravidez e parto estão expostos a inúmeras manifestações de angústia, de medo e apreensão, e precisam lidar com conteúdos inconscientes que vêm à tona em virtude da experiência que as mulheres estão vivenciando. Para evitar o uso de mecanismos defensivos que afastam o profissional do contato próximo com as mulheres e que o impele a adotar atitudes pouco empáticas e que não dão conta do adequado manejo dos aspectos emocionais das pacientes e de suas famílias, parece imprescindível que se repense o apoio prestado a esses profissionais pela própria instituição, e que se revejam questões ligadas à formação profissional.

O Eixo II, denominado "Um mundo à parte: a experiência de dar à luz no contexto hospitalar", pretendeu abordar as questões ligadas à rotina de atendimento às mulheres internadas em um Centro Obstétrico, trazendo à tona aspectos que se repetiram ao longo do trabalho e que foram revelando padrões. Segundo Bick (1964), o método permite delinear padrões de conduta que se tornam significativos quando se repetem ao longo do tempo, em sucessivas observações.

O Centro Obstétrico foi descrito em inúmeros relatos como um mundo à parte: um ambiente diferente de tudo que se costuma ver no dia a dia, que lida com o corpo e com a alma das mulheres de uma forma peculiar. A característica de urgência do setor foi um ponto que chamou a atenção da observadora e faz pensar em como a inconstância, a falta de garantias sobre os acontecimentos futuros e a incapacidade de saber ou de prever o fim ou o início de um evento são desorganizadores e potencialmente traumáticos (Winnicott, 1949/2000):

[a parturiente] afirmava com convicção que estava mal, $e$ que não tinha mais forças. Me perguntou quanto tempo ainda iria demorar para o parto, e disse que en não sabia. [...] Nessas horas, tenho vontade de dizer alguma coisa, mas ao mesmo tempo sei que não tenho nada para dizer. Nada do que en diga on faça vai resolver o problema. Diane estava com dor, pedia ajuda, mas o que ela queria era pôr um fim naquilo tudo, e eu não podia resolver isso para ela. (Obs. 67)

A dificuldade de comunicação foi outro padrão que se estabeleceu durante as sucessivas observações, e que pode ser constatada pelas dificuldades que os 
profissionais tinham de entender o que a parturiente realmente estava comunicando, ou mesmo de se fazer entender por ela, em um nível que ia além da linguagem verbal. Essa questão parece remeter à necessidade da parturiente, que se encontra em uma condição regredida, sensível e vulnerável (Winnicott, 1968/1999; 1956/2000), de um cuidador que seja capaz de comunicar-se com ela por outras vias que não apenas a da palavra falada:

[a parturiente] queixou-se que estava se sentindo mal e que achava que ia desmaiar. [...] [a técnica em enfermagem] explicou para [a parturiente] que ela devia estar um pouco tonta por não estar respirando, e que mesmo quando viesse a dor, não podia esquecer de respirar. Explicou para as colegas e para mim que quase todas as parturientes, no momento da dor, trancam a respiração e acabam ficando sem ar. Acho que não era bem aquilo que Rosaura queria ouvir, talvez. não era bem aquela ajuda que ela queria on precisava. (Obs. 70 )

E é justamente a capacidade de identificar-se com essa mulher que possibilitará ao seu cuidador, profissional ou não, estabelecer uma comunicação que realmente vá ao encontro de suas necessidades, especialmente as de ordem emocional. Retomando, uma vez mais, o estado regressivo em que a mãe se encontra (Caron, Fonseca \& Lopes, 2008), identificada com o bebê e reconectada com o seu próprio nascimento (Winnicott, 1956/2000), é possível pensar que um ambiente inconstante, sujeito à emergência e ao imprevisto e com dificuldades de comunicação não oferece à mulher condições para que ela se mantenha psicologicamente organizada e consiga lidar com as demandas emocionais provocadas pela iminência do parto.

No processo de descortinamento da experiência do parto, objetivo deste trabalho, o Eixo III, denominado "A experiência feminina do parto: a busca por um novo nascimento", possibilitou a investigação de questões até então teóricas sobre o fenômeno. Um dos aspectos mais comuns evidenciados pelas mulheres que estão vivenciando o processo de nascimento de um filho, e que se repetiu ao longo de todas as observações, é a dor. A dor do parto já foi alvo de inúmeros estudos e discussões (Donelli, 2003; Lebovici, 1987; Terry \& Gijsbers, 2000), mas nenhum destes trabalhos utilizou observação para conhecer fenômeno. No presente estudo, inúmeras manifestações de dor puderam ser observadas. A maioria delas estava ligada à evolução do trabalho de parto, ao aumento da intensidade e à diminuição dos intervalos das contrações.

Talvez o fato de não saber por quanto tempo será necessário suportar as dores, além de não ter respostas da equipe para essa dúvida, corroboram a crença das mulheres de que aquele sofrimento não terá fim, ou será insuportável:

O médico voltou por volta das 18 horas, e examinou [a parturiente] novamente. Ela lhe suplicava ajuda, e ele disse que a ajudaria. Mas para isso ela precisaria seguir suas orientações. Na contração, ele pediu que ela fizesse força para o bebê nascer, e elogiou a força $[d a$ paciente]. Isso se repetiu umas três vežes, e então ele pediu que [a técnica em enfermagem] levasse [a parturiente] para a mesa de parto. Ela passou por mim, amparada por [técnica de enfermagem], e sorriu. Aquela expressão, apesar de revelar um medo terrivel, era também uma expressão de alivio. Era essa ajuda que queria, isto é, que alguém determinasse o fim daquele suplicio? (Obs. 57)

Essa sensação de não saber quando um sofrimento terminará pode evocar nas mulheres ansiedades de tipo primitivo, pois é uma situação que pode ser percebida como ameaça à própria condição de continuar existindo. Além disso, o parto tem o potencial de transformar-se em uma situação traumática para a mulher que dá à luz, na medida em que a obriga a lidar com sentimentos de perda e separação do próprio filho. Já o bebê que está nascendo experimentaria uma situação de desamparo oriunda $\mathrm{da}$ incapacidade de dominar psiquicamente a crescente tensão que se instala por conta da excessiva quantidade de estímulos. Assim, a angústia ligada ao nascimento seria, sobretudo para o bebê, provocada pela angústia de aniquilamento, enquanto para a mulher, além da angústia de aniquilamento provavelmente revivida por conta da experiência do parto e de sua condição fragilizada e regredida, ela estaria também vivenciando angústia de separação.

A dor do parto não estaria, portanto, também relacionada à dor da perda, não apenas física, mas também emocional? Essa questão pode ser entendida como a revelação do desamparo (Donelli, Caron \& Lopes, 2012) ao qual as mulheres estão expostas em função da perda de sua condição de grávida e à separação concreta de um ser que a habitou por meses, compartilhando de suas entranhas de uma forma que até mesmo elas desconhecem. A sensação de vazio pode estar denunciando também a perda concreta de uma parte de si mesma. O fato de segurar a própria barriga vazia, como fez umas das parturientes após o nascimento do bebê, parece revelar a necessidade de segurar-se, de se autoconter para não se perder nessa avalanche de sentimentos que a invadem nesse momento:

Em dado momento, para surpresa de todos que estavam por ali, [a paciente] exclamou, quase assustada, que não tinha mais a barriga. [...] [a 
paciente] apalpava sua barriga e levantava o avental para olhar-se. (Obs. 23); e Os olhos [da paciente] brilhavam, mesmo depois de sua bebê ter sido levada para a sala de admissão. Ela colocon a mão sobre a barriga e exclamou que já não tinha mais nada na barriga, e que era estranho. (Obs. 67)

Nesse sentido, a exaustão, o cansaço e o desgaste das mulheres, tanto durante o trabalho de parto como imediatamente após o nascimento do bebê, e que ficaram evidentes para a observadora, remetem também a esse esforço emocional extremo para dar conta de sentimentos de angústia de fragmentação, de aniquilamento e de separação. O esgotamento e a sensação de ter se perdido foram experimentados também pela observadora, o que corrobora a id eia de que esses conteúdos inconscientes faziam parte da vivência emocional da mãe.

As mulheres também evidenciaram um movimento chamado pela observadora de alienação: uma espécie de estado alterado de consciência que fazia com que ficassem alheias ao mundo ao seu redor, interagissem pouco com o ambiente à sua volta, verbalizassem pouco e até dormissem durante a evolução do trabalho de parto:

Havia quatro pacientes ali, todas bastante quietas, como se estivessem dormindo. [...] [a paciente] permanecen quase todo o tempo deitada e virada para a parede. Consegui ver seu rosto apenas em um momento que ela se sentou na cama e se ajeitou para virar de lado. [...] Ela me vin ali parada, e sorriu, para novamente se deitar e desaparecer - às vezes lembro do mar, e de como essas mulheres parecem mergulhar num mar sem fim, vindo à superfície em poucos momentos, talvez. para mostrar que ainda estão ali. $\mathrm{Na}$ verdade, se sabe que elas estão ali, mas não se sabe muito bem por onde andam. (Obs. 62)

Esse movimento de vir à tona e aproximar-se da superfície, para em seguida mergulhar nas profundezas de seu próprio inconsciente pode ser entendido como uma defesa contra a avalanche de sentimentos e sensações que as mulheres poderiam estar experimentando. Essa alienação, entendida como uma proteção contra intrusões ambientais e contra a perturbação do senso de continuar existindo, também pode estar revelando, além de um mecanismo de defesa, uma espécie de identificação com o bebê.

Pode-se aventar algumas hipóteses para esse movimento da mulher, chamado aqui de alienação, mas talvez mais bem definido como um movimento de alternância entre o mundo externo e o mundo interno. Uma das hipóteses diz respeito a esse movimento como uma forma de defesa contra estímulos percebidos como excessos para a mãe. Assim, ao sentir a ameaça, a mulher desencadearia, inconscientemente, uma espécie de desconexão com o mundo que a cerca, evidenciada pelo comportamento alheio e distante. A outra hipótese estaria relacionada à maciça identificação da mulher com o seu bebê, o que a faria experimentar um estado de torpor semelhante ao do bebê dentro do útero. É possível, entretanto, identificar nessa segunda hipótese um caráter defensivo semelhante ao da primeira. E uma terceira hipótese estaria relacionada à necessidade da mulher de voltar-se exclusivamente para si durante o trabalho de parto e o parto, corroborando a ideia de que o parto é um evento feminino por excelência, e é a mulher a atriz principal nesse palco dos acontecimentos. Entretanto, quase sempre o bebê é tomado como o personagem principal, relegando a mulher a segundo plano, desvalorizando seus sentimentos e sua necessidade de auxílio para elaborar psiquicamente a experiência (Lopes \& cols., 2005; Peterson, 1996).

O movimento de alienação testemunhado pela observadora assemelha-se ao estado de retraimento descrito por Winnicott (1972/1991,1954/2000) e definido como um desligamento momentâneo de uma relação com a realidade externa durante a vigília, assemelhando-se a um breve sono. Para o autor, o paciente busca inconscientemente esse estado de retraimento com o objetivo de garantir uma sustentação para o próprio eu. Se, nesse momento, o paciente conseguir obter do ambiente uma sustentação semelhante à que ele procura, então o que até ai se configurava como um simples retraimento pode transformar-se em regressão. A vantagem da regressão é a de que ela traz consigo a possibilidade de corrigir experiências anteriores e de transformar-se em algo produtivo. Assim, mais uma vez pode-se pensar no papel dos profissionais que assistem a mulher durante o parto, os quais muitas vezes evitam o estabelecimento de uma relação de dependência com o paciente, pois esta pode ser muito intensa e difícil de suportar. Entretanto, seria somente por meio da sustentação do paciente e da possibilidade de lidar com a dependência que seu estado regressivo evoca, que seria possível oferecer um espaço para o crescimento pessoal. Talvez em função disso o que se tenha percebido nas observações, e que se repetiu inúmeras vezes, foi apenas um estado de retraimento, desassistido e incompreendido pela equipe.

Para finalizar, retomando as ideias iniciais de que tornar-se mãe e pai possibilita a revivência de etapas iniciais do desenvolvimento, agora na posição de genitores (Colarusso, 1990; Levandowski, Piccinini \& Lopes, 2009), acredita-se que, pela aplicação do método Bick no Centro Obstétrico, foi possível entrar em contato com emoções primitivas, reativadas durante o trabalho de parto, em razão da condição de 
fragilidade e regressão da mãe, o que aproxima a vivência emocional da mãe da vivência emocional do bebê. O potencial traumático do parto, pela quebra de continuidade, salientado em relação ao bebê (Winnicott, 1949/2000), pode também ser pensado em relação à mãe. $\mathrm{O}$ ambiente observado neste estudo, com todas as suas características, pode representar uma intrusão ambiental que leva a uma interrupção do senso de continuidade, do existir da mãe, sobretudo se considerarmos a sua condição de fragilidade e regressão.

\section{Considerações finais}

A principal questão a se considerar em relação à utilização do Método Bick em pesquisa é a possibilidade de o pesquisador contribuir também com seu próprio mundo interno, facilitando ou não o acesso a questões relevantes no estudo proposto. Aqui cabe destaque ao que pode ser considerado também uma limitação do Método Bick e deste trabalho. A mobilização interna do pesquisador pode interferir negativamente com o curso do processo de observação, impedindo o acesso a dados relevantes em função das limitações do próprio observador/pesquisador. Outra questão importante a ser considerada é a necessidade de treinamento prévio no Método Bick, com o objetivo de minimizar esses entraves do observador.

Apesar disso, os dados trazidos pela observadora neste trabalho apontam uma série de questões passíveis de reformulação quando se pensa na assistência ao parto. Uma delas trata da necessidade do profissional de dar conta de uma demanda de ordem psicológica e emocional. Outra necessidade diz respeito à importância de desenvolver características pessoais em direção ao autoconhecimento, com o objetivo de poder dar conta dessa demanda anteriormente citada. Também se faz necessário buscar novos conhecimentos técnicos e científicos, especialmente aqueles relacionados à compreensão da vivência emocional da mulher no momento do parto, para respaldar a revisão da prática profissional. Nesse sentido, parece já não bastar às equipes compartilhar seu dia a dia apenas com profissionais das áreas médicas e de enfermagem. Abre-se aqui um campo importante de atuação para o profissional da psicologia - o Centro Obstétrico e a obstetrícia - seja na assistência direta às pacientes, seja na assistência direta aos profissionais, ou no desenvolvimento de programas de capacitação. $\mathrm{O}$ conhecimento psicológico acumulado em relação a essa especialidade médica, e em especial em relação ao parto, abre um campo ainda novo para a prática psicológica.
Essas questões apontam para as implicações clínicas deste estudo. A aplicação do Método Bick em hospital e, mais especificamente, em um Centro Obstétrico, permite supor que seu uso como estratégia de intervenção nesse contexto é viável e até desejável. A possibilidade de oferecer um novo modelo de intervenção, pautado no respeito à individualidade, ao ritmo e às necessidades de cada um, está implícita neste trabalho. A figura da observadora como alguém que conseguia se comunicar efetivamente com as pacientes, que podia vê-las de outra forma, levando em conta seu mundo interno, que realizava sua tarefa de forma tranquila, constante e coerente, que respeitava os limites da intervenção, que conseguia conter a carga bruta e por vezes hostil de projeções oriundas tanto das mulheres quanto dos profissionais, sem, no entanto, perder-se ou fragmentar-se, ofereceu a todos um novo referencial, mostrando que é possível fazer seu trabalho de outra forma.

Enfim, espera-se que este trabalho tenha contribuído para descortinar a vivência feminina do parto, bem como para repensar questões ligadas à assistência prestada nesse momento de intensa mobilização psíquica. Ao ampliar a discussão sobre o parto e sobre a melhor maneira de cuidar das mulheres nesse momento, acredita-se estar prestando uma importante contribuição para que, em um futuro próximo, encontrem-se formas de garantir a elas um novo nascimento, mediante de uma assistência capaz de acolhê-las, compreendê-las e respeitá-las no sentido mais amplo dessas palavras. Compreendê-las não apenas nas manifestações somáticas, mas principalmente nas suas expressões emocionais. E respeitá-las na sua individualidade, no seu ritmo e nas suas necessidades. Isso talvez permitisse à mulher experimentar o parto como uma transição o mais contínua possível em direção a uma nova fase de seu desenvolvimento pessoal.

\section{Referências}

Anzieu, D. (2000). O Eu-pele (Z. Yazigi \& R. Mahfuz, Trads.). São Paulo: Casa do Psicólogo.

Bick, E. (1964). Notes on infant observation in psychoanalytic training. International Journal of Psychoanalysis, $X L V, 4,97-115$.

Bick, E. (2002). The experience of the skin in early object relations. Em A. Briggs \& D. Meltzer (Eds.). Surviving space: papers on infant observation (pp. 55-59). London: Karnac Books. (Original publicado em 1968).

Bion, W. R. (1991). O aprender com a experiência (P. D. Corrêa, Trad.). Rio de Janeiro: Imago. (Original publicado em 1962) 
Birksted-Breen, D. (2000). The experience of having a baby: A developmental view. Em J. Raphael-Leff (Org.). 'Spilt milk', perinatal loss and breakdown (pp. 17-27). Londres: Institute of Psychoanalysis.

Caron, N. A., Fonseca, M. \& Lopes, R. C. S. (2008). The baby and his majesties: some reflexions on human helplessness. Infant Observation, 11(1), p. 6776.

Colarusso, C. A. (1990). The third individuation: the effect of biological parenthood on separationindividuation process in adulthood. Psychoanalitic Study of the Child, 45, 179-194.

Colarusso, C. A. (1997). Separation-individuation process in middle adulthood: the fourth individuation. Em S. Akhtar \& S. Kramer (Orgs.). The seasons of life: separation-individuation perspectives (pp. 73-94). Northvale: Jason Aronson.

Czarnocka, J. \& Slade, P. (2000). Prevalence and predictors of post-traumatic stress symptoms following childbirth. British Journal of Clinical Psychology, 39, 35-51.

Donelli, T. M. S. (2003). O parto no processo de transição para a maternidade. Dissertação de mestrado nãopublicada, Programa de Pós-Graduação em Psicologia do Desenvolvimento, Universidade Federal do Rio Grande do Sul.

Donelli, T. M. S., Caron, N. A. \& Lopes, R. C. S. (2012). A experiência materna do parto: confronto de desamparos. Revista de Psicanálise da Sociedade Psicanalítica de Porto Alegre, 19(2), 395-414.

Durik, A. M., Hyde, J. S. \& Clark, R. (2000). Sequelae of cesarean and vaginal deliveries: psychosocial outcomes for mothers and infants. Developmental Psychology, 2(36), 251-260.

Jardin, F., Detry, L., Denis, P., Moreau, A., \& Silbernann, (1997). A observação do bebê na creche. Em M. B. Lacroix \& M. Monmayrant (Orgs.) (F. F. Settineri, Trad.). Os laços do encantamento: a observação de bebês segundo Esther Bicke $e$ suas aplicações (pp. 163-174). Porto Alegre: Artes Médicas.

Klein, M. (1969). Sobre a identificação. Em M. Klein, P. Heimann \& R. E. Money-Kyrle (Orgs.). Temas de Psicanálise Aplicada. Rio de Janeiro: Zahar.

Lebovici, S. (1987). O bebê, a mãe e o psicanalista. Porto Alegre: Artes Médicas.

Levandowski, D., Piccinini, C. A., \& Lopes, R. C. S. (2009). O processo de separação-individuação de adolescentes do sexo masculino na transição para a paternidade. Psicologia: Reflexão e Crítica, 22, 317328.

Lopes, R. C. S., Donelli, T. M. S., Lima, C. M. \& Piccinini, C. A. (2005). O antes e o depois: expectativas e experiências de mães sobre o parto. Psicologia: Reflexão e Crítica, 18(2), 247-254.

Lopes, R. de C. S., Vivian, A. G., Oliveira-Menegotto, L. M. de, Donelli, T. M. S. \& Caron, N. A. (2007). A observação da relação mãe-bebê através do método Bick. Em C. A. Piccinini \& M. L. S. de Moura (Eds.). Observando as interaçôes pais-bebêcriança: diferentes abordagens teóricas e metodológicas. São Paulo: Casa do Psicólogo.

Marin, A, Donelli, T. M. S., Lopes, R. C. S. \& Piccinini, C. A. (2009). Expectativas e sentimentos de mães solteiras sobre a experiência do parto. Aletheia, 29(1), 57-72.

Martini, I. I. (2000). Em uma enfermaria de cardiologia pediátrica: uma aplicação do método de ORMB. Em N. Caron (Org.). A relação pais-bebê: da observação à clínica (pp. 233-249). São Paulo: Casa do Psicólogo.

Mascaro, M. S., Calderon, I. M. P., Costa, R. A. A., Maestá, I., Bossolan, G. \& Rudge, M. V. C. (2002). Cardiotocografia anteparto e prognóstico perinatal em gestações complicadas pelo diabete: influência do controle metabólico materno. Revista Brasileira de Ginecologia e Obstetrícia, 24(9), 593-599.

Melender, H.-L. (2002). Experiences of fears associated with pregnancy and childbirth: a study of 329 pregnant women. Birth, 29(2), 101-111.

Oliveira-Menegotto, L. M. de (2007). O desamparo materno diante de seu bebê com Síndrome de Down: aplicação do Método Bick de observação da relação mãe-bebê. Tese de doutorado nãopublicada, Programa de Pós-Graduação em Psicologia do Desenvolvimento, Universidade Federal do Rio Grande do Sul.

Oliveira-Menegotto, L. M. de, Menezes, C. C., Caron, N. A. \& Lopes, R. de C. S. (2006). O método Bick de observação de bebês como método de pesquisa. Psicologia Clínica, 18(2), 77-96.

Peterson, G. (1996). Childbirth: the ordinary miracle: effects of devaluation of childbirth on women's self-esteem and family relationships. Pre and Perinatal Psychology Journal, 11, 101-109.

Piontelli, A. (1995). De feto a crianca (J. Wilheim, N. L. Gomes, S. M de Godoy, Trad.). Rio de Janeiro: Imago.

Rustin, M. (1989). Observing infants: reflections on methods. Em L. Miller, M. E. Rustin, M. J. Rustin e J. Shuttleworth (Orgs.), Closely Observed Infants. London: Duckworth.

Rustin, M. (1997). What do we see in Nursery? Infant observation as laboratory work. Infant observation: the international journal of infant observation and its applications, 1(1), 71-83. 
Ryding, E. L., Wijma, K. \& Wijma, B. (2000). Emergency cesarean section: 25 women's experiences. Journal of Reproductive and Infant Psychology, 18(1), 33-39.

Soet, J. E., Brack, G. A. \& Dilorio, C. (2003). Prevalence and predictors of women's experience of psychological trauma during childbirth. Birth, 30, 36-46.

Steibel, D. (2011). As vivências primitivas de um bebê nascido extremamente prematuro no ambiente da UTI neonatal: uma aplicação do Método Bick de observação. Dissertação de mestrado nãopublicada, Programa de Pós-Graduação em Psicologia. Universidade Federal do Rio Grande do Sul.

Terry, R. \& Gijsbers, K. (2000). Memory for the quantitative and qualitative aspects of labour pain: a preliminary study. Journal of Reproductive and Infant Psychology, 18(2), 143-152.

Vivian, A. G. (2006). O desenvolvimento emocional de um bebê em uma família numerosa: uma aplicação do método. Dissertação de mestrado não-publicada, Programa de Pós-Graduação em Psicologia do Desenvolvimento, Universidade Federal do Rio Grande do Sul.

Winnicott, D. W. (1990a). Teoria do relacionamento paterno-infantil (I. C. S. Ortiz, Trad.). Em D. W. Winnicott. $O$ ambiente e os processos de maturação (pp. 38-54). Porto Alegre: Artes Médicas. (Original publicado em 1960).

Winnicott, D. W. (1990b). O desenvolvimento da capacidade de se preocupar (I. C. S. Ortiz, Trans.). Em D. W. Winnicott, $O$ ambiente e os processos de maturação (pp. 70-78). Porto Alegre: Artes Médicas. (Original publicado em 1963).
Winnicott, D. W. (1991). Holding e interpretação (S. M. Tavares \& M. de Barros, Trads.). São Paulo: Martins Fontes. (Original publicado em 1972).

Winnicott, D. W. (1999a). A contribuição da psicanálise à obstetrícia (J. L. Camargo, Trad.). Em D. W. Winnicott. Os bebês e suas mães (pp. 61-71). São Paulo: Martins Fontes. (Original publicado em 1957).

Winnicott, D. W. (1999b). A amamentação como forma de comunicação (J. L. Camargo, Trad.). Em D. W. Winnicott. Os bebês e suas mães (pp. 19-27). São Paulo: Martins Fontes. (Original publicado em 1968).

Winnicott, D. W. (2000a). Memórias do nascimento, trauma do nascimento e ansiedade (D. Bogomoletz, Trad.). Em D. W. Winnicott. Da pediatria à psicanálise: obras escolbidas (pp. 254-276). Rio de Janeiro: Imago. (Original publicado em 1949).

Winnicott, D. W. (2000b). Retraimento e regressão (D. Bogomoletz, Trad.). Em D. W. Winnicott. Da pediatria à psicanálise: obras escolbidas (pp. 347-354). Rio de Janeiro: Imago. (Original publicado em 1954).

Winnicott, D. W. (2000c). A preocupação materna primária (D. Bogomoletz, Trad.). Em D. W. Winnicott. Da pediatria à psicanálise: Obras escolbidas (pp. 399-405). Rio de Janeiro: Imago. (Original publicado em 1956).

Recebido em 27/09/2012

Reformulado em 06/02/2013

Aprovado em 26/03/2013 
Nota das autoras:

Este trabalho é derivado da tese de doutorado da primeira autora (Donelli, T. M. S. (2008). Descortinando a vivência emocional de mulheres em um centro obstétrico: uma investigação sobre o parto através do Método Bick. Tese de Doutorado NãoPublicada, Programa de Pós-Graduação em Psicologia, Universidade Federal do Rio Grande do Sul, Porto Alegre. 195 p.), sob orientação da segunda.

Sobre as autoras:

Tagma Marina Schneider Donelli é psicóloga, doutora em Psicologia pela Universidade Federal do Rio Grande do Sul (UFRGS), professora e pesquisadora do Programa de Pós-Graduação em Psicologia Clínica da Universidade do Vale do Rio dos Sinos (UNISINOS). Trabalha com o Método Bick em pesquisa, tendo realizado trabalhos de aplicação deste método em sala de parto.

Rita de Cássia Sobreira Lopes é PhD pela Universidade de Londres, professora do Instituto de Psicologia da Universidade Federal do Rio Grande do Sul (UFRGS) e está vinculada ao programa de Pós-Graduação em Psicologia, na área de Psicologia do Desenvolvimento, com ênfase em Desenvolvimento Emocional. Desenvolve pesquisas sobre o desenvolvimento emocional primitivo, incluindo a gravidez, parto e relação pais-bebê.

Contato com as autoras:

Av. Unisinos, 950 - sala 2A110 - Bairro Cristo Rei - CEP 93022-000 - São Leopoldo-RS, Brasil E-mail: tagmad@unisinos.br 